\title{
Enhancement the Thermal Stability and the Mechanical Properties of Acrylonitrile-Butadiene Copolymer by Grafting Antioxidant
}

\author{
Abdulaziz Ibrahim Al-Ghonamy, ${ }^{1}$ A. A. El-Wakil, ${ }^{1,2}$ and M. Ramadan ${ }^{1,3}$ \\ ${ }^{1}$ Faculty of Engineering, Hail University, Saudi Arabia \\ ${ }^{2}$ National Institute of Standards, Tersa Street, El-Harm, P.O. Box 136, Giza 12211, Egypt \\ ${ }^{3}$ Central Metallurgical Research and Development Institute, P.O. Box 87, Helwan 11421, Egypt
}

Correspondence should be addressed to A. A. El-Wakil, abdelaziz_elwakil@yahoo.com

Received 11 September 2009; Accepted 6 November 2009

Academic Editor: Giridhar Madras

Copyright ( $) 2010$ Abdulaziz Ibrahim Al-Ghonamy et al. This is an open access article distributed under the Creative Commons Attribution License, which permits unrestricted use, distribution, and reproduction in any medium, provided the original work is properly cited.

\begin{abstract}
Monomeric antioxidants are widely used as effective antioxidants to protect polymers against thermal oxidation. Low molecular weight antioxidants are easily lost from polymer through migration, evaporation, and extraction. Physical loss of antioxidants is considered to be major concern in the environmental issues and safety regulation as well as long life time of polymers. The grafting copolymerization of natural rubber and $o$-aminophenol was carried out by using two-roll mill machine. The prepared natural rubber-graft-o-Aminophenol, NR-graft-o-AP, was analysed by using Infrared and ${ }^{1} \mathrm{H}-\mathrm{NMR}$ Spectroscopy techniques. The thermal stability, mechanical properties, and ultrasonic attenuation coefficient were evaluated for NBR vulcanizates containing the commercial antioxidant, $\mathrm{N}$-phenyl- $\beta$-naphthylamine (PBN), the prepared grafted antioxidant, NR-graft-o-AP, and the control vulcanizate. Results of the thermal stability showed that the prepared NR-graft-o-AP can protect NBR vulcanizate against thermal treatment much better than the commercial antioxidant, PBN, and control mix, respectively. The prepared grafted antioxidant improves the mechanical properties of NBR vulcanizate.
\end{abstract}

\section{Introduction}

Polyolefin is one of the most widely used polymers and more susceptible to the oxidation. It well known that oxidation reactions increase at elevated temperatures during the processing of the polymer. All polymers will degrade when exposed to certain environmental conditions such as high temperatures, mechanical shear, and high-energy radiation (e.g., UV exposure). The presence of oxygen will often accelerate this degradation. The first step in the degradation process is usually the loss of hydrogen atom from the polymer chain due to this energy input. This polymer "free radical", $\left[\mathrm{R}^{*}\right]$, can then react with an oxygen $\left(\mathrm{O}_{2}\right)$ molecule to form peroxy radical [ROO* ${ }^{*}$ which will in turn abstract hydrogen atom from another polymer chain to form hydroperoxide $[\mathrm{ROOH}]$. The hydroperoxide can split into two new free radicals, $\left[\mathrm{RO}^{*}\right]+\left[{ }^{*} \mathrm{OH}\right]$, which continue to propagate the reaction to other polymer molecules. For certain polymers, such as acrylonitrile-butadiene copolymer, a polymer chain containing free radical is likely to split into two smaller chains [1-3].

One way to interrupt this process is to incorporate an antioxidant into the acrylonitrile-butadiene copolymer. There are different types of antioxidants that interrupt the degradation cycle: primary antioxidants, secondary antioxidants, multifunctional antioxidants, hydroxylamines, carbon-centered radical scavengers, and grafted antioxidants. Higher molecular weight compounds, such as grafted antioxidant, are less volatile and more effective at higher temperatures and at longer exposure times. The estimation of stabilizers efficiency is necessary for the correct choice of the most active stabilizers for practical use [4-7]. Therefore we synthesized Natural rubber-graft-o-Aminophenol and tested as grafted antioxidants. 

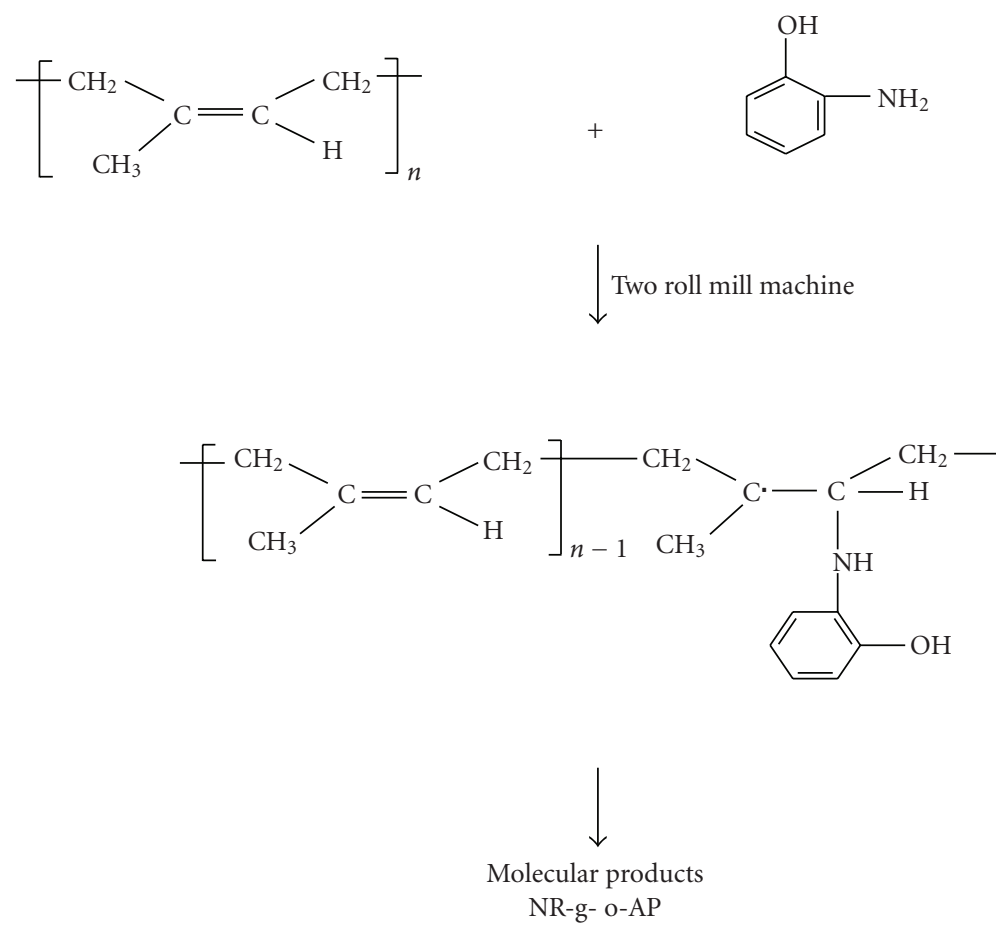

FIgURE 1

\section{Experimental}

2.1. Materials. o-Aminophenol was supplied by SigmaAldrich Co. Ltd. (Steinheim, Germany). Acrylonitrilebutadiene copolymer, with the trade name Humex N-34/47, was obtained from Polymer Corp., France. Natural rubber was supplied by (Ningbo Yonggang Industry Development Co., Ltd., China). All laboratory grade solvents were obtained from Edwic (Cairo, Egypt).

2.2. Synthesis of NR-graft-o-AP. NR-graft-o-AP was synthesized by the reaction of natural rubber and $o$-Aminophenol using two-roll mill machine. Natural rubber was masticated on a water-cooled two-roll mill $150 \mathrm{~mm}$ in diameter and $300 \mathrm{~mm}$ wide. The masticated NR after treatment with $o$ AP was dissolved in toluene, and the mixture solution was filtrated. The ungrafted NR was precipitated by boiling in ethanol. A rotating evaporator is used to isolate the grafted NR. The product was dried in an oven at $40^{\circ} \mathrm{C}$ to constant weight within 24 hours. The percent graft was taken as the ratio of the graft yield to the natural rubber multiplied by $100[8]$ :

$$
\text { Degree of grafting }=\left(\frac{\mathrm{Wg}}{\mathrm{WNR}}\right) * 100
$$

where Wg is the weight of graft yield and WNR is the weight of natural rubber.

The degree of grafting of the prepared natural rubbergraft-o-aminophenol is $18.32 \%$. The synthesis of NR-graft$o$-AP is shown in Figure 1.
2.3. Formulation and Mixing of NBR Vulcanizates. The NBR rubber vulcanizates were compounded according to the recipe shown in Table 1 . The ingredients were added in the same order as listed.

All NBR vulcanizates masterbatche was mixed on two roll mill at $45^{\circ} \mathrm{C}$ to $55^{\circ} \mathrm{C}$. The rubber mixes were vulcanized at $152^{\circ} \mathrm{C}$ with an electric press for the optimum cure time, which was indicated by a Monosanto rheometer (Swindon, UK).

Zinc oxides and stearic acid were added to "activate" the accelerators to act fast in vulcanizing rubber. When elemental sulfur is used as the vulcanizing agent, certain auxiliary materials must add to obtain the desirable properties. The most important of these materials is the organic accelerator. The most common method of crosslinking NBR is using sulfur. The function of sulfur is forming a bridge between large chains of NBR, linking them together in a fixed pattern.

Antioxidants are substances that retard oxidation by atmospheric oxygen at moderate temperatures (autoxidation). Autoxidation is a free radical chain reaction that can be inhibited at the initiation and propagation steps.

2.4. Infrared and ${ }^{1} \mathrm{H}$-NMR Spectroscopy. IR spectra and ${ }^{1} \mathrm{H}-$ NMR spectra were registered on Bruker, Vector22, FTIR Spectrometer, and Jeol-EX-270, respectively.

2.5. Mechanical Measurements. Mechanical tests were performed according to the ASTM D 412 test method and were carried out using a Zwick tensile testing machine (model Z010, August-Nagel-Strassell, D-89079, Ulm, Germany) at $23^{\circ} \mathrm{C} \pm 2{ }^{\circ} \mathrm{C}$ and a crosshead speed was $500 \mathrm{~mm} / \mathrm{min}$. Five samples per each NBR vulcanizate were tested [9]. 
TABLE 1: Formulation of NBR vulcanizates containing PBN, NR-g-o-AP, and control vulcanizate.

\begin{tabular}{|c|c|c|c|}
\hline \multirow{2}{*}{ Ingredient (phr) $\downarrow$} & \multicolumn{3}{|c|}{ Mix name } \\
\hline & A1 & $\mathrm{A} 2$ & $\mathrm{~A} 3$ \\
\hline NBR & 100 & 100 & 100 \\
\hline $\mathrm{ZnO}$ & 5 & 5 & 5 \\
\hline Stearic acid & 2 & 2 & 2 \\
\hline Processing oil & 5 & 5 & 5 \\
\hline Semireinforcing furnace (SRF) & 30 & 30 & 30 \\
\hline Sulfur & 1.5 & 1.5 & 1.5 \\
\hline Mercaptobenzthiazole "MBT" & 0.75 & 0.75 & 0.75 \\
\hline Tetramethylthiuramdisulphide "TMTD" & 0.75 & 0.75 & 0.75 \\
\hline N-phenyl- $\beta$-naphthylamine "PBN" & - & 1 & - \\
\hline NR-graft-o-AP & - & - & 5 \\
\hline Cure time (min.) & 8 & 6 & 9.5 \\
\hline
\end{tabular}

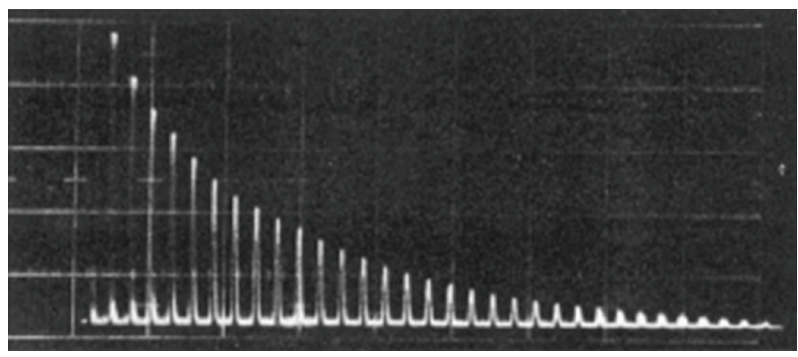

Typical pulse-echo decay pattern

FIGURE 2

2.6. Ultrasonic Testing Method. Ultrasonic waves are a kind of mechanical waves with frequency more than $20 \mathrm{kHz}$. Ultrasonic waves can be generated from a piezoelectric transducer, and then they propagate in the tested samples. In this study, the ultrasound measurements were performed using an ultrasound flaw detector (USIP 20, Krautkramer, Germany), an oscilloscope (54615B, $h p$, USA), and a longitudinal transducer ( $4 \mathrm{MHz}$, Krautkramer, Germany).

The incident waves were transmitted in a sample of thickness X and reflected back and forth at the two surfaces. When the reflected waves reached the upper surface and were received by the transducer, multiple echo signals appeared on the screen of the Flaw detector. However, the amplitudes of the echo signals are gradually decreased with time due to ultrasonic attenuation (see Figure 2).

The first two echo signals, of amplitudes (A1, A2) and corresponding time $(\mathrm{t} 1, \mathrm{t} 2)$, can be read and chosen to calculate the ultrasonic attenuation $\alpha$ [10]:

$$
\alpha=\frac{20 \log _{10}\left(A_{1} / A_{2}\right)}{2 X} .
$$

The measurements of ultrasonic attenuation were repeated three times to check the reproducibility of the data. The estimated accuracies were $0.04,0.05$, and $0.07 \%$, respectively.

2.7. Thermal Analysis. Thermogravimetric analysis (TGA) was used to study the thermal degradation of the acrylonitrile-butadiene rubber vulcanizates which contain the commercial antioxidant $(\mathrm{PBN})$ and the prepared grafted antioxidant (natural rubber-graft-o-aminophenol) as well as the control vulcanizate. The measurements were carried out at temperatures ranged from $23^{\circ} \mathrm{C}$ to $750^{\circ} \mathrm{C}$ with heating rate of $10^{\circ} \mathrm{C} / \mathrm{min}[11]$.

\section{Results and Discussion}

Thermal and mechanical degradation processes proceeding in the presence of oxygen have free radical character. Independent of the manner of the initiations generating the primary free-radical species, oxygen centered radicals and hydroperoxides are formed in the chain propagation steps and carbon centered radicals are regenerated. In the absence of oxygen, alkyl radicals are consumed in self-termination reactions. In the presence of oxygen, they are quickly oxidized to $\mathrm{ROO}$, and the free radical chain oxidation governs the degradation of the NBR chains. Therefore the studying of the effect of the prepared grafted antioxidant, NR-graft- $o$-AP, on the thermal stability and the mechanical properties of the NBR vulcanizates became obligatory.

3.1. Analysis of NR-graft-o-AP. Figures 3, 4, and 5 show the IR spectra of $o$-AP, original (ungrafted) NR, and the natural rubber-graft- $O$-aminophenol.

Figures 6 and 7 show the ${ }^{1} \mathrm{H}-\mathrm{NMR}$ spectra of original (ungrafted) NR and the natural rubber-graft-o-aminophenol.

The assignments of various peaks found in Figures 35 show significant changes in the spectral behaviour of the natural rubber and $o$-aminophenol. The new absorption peak at $3375 \mathrm{~cm}^{-1}$ which corresponded to the $\mathrm{OH}$ group of $o$ $\mathrm{AP}$ and the intensity of the $\mathrm{C}=\mathrm{C}$ in NR is decreased in the IR spectrum of NR-g-o-AP. Figures 6 and 7 show the ${ }^{1} \mathrm{H}-\mathrm{NMR}$ spectra of the natural rubber and natural rubber-graft-oaminophenol. Figure 7 shows additional peaks at $6.5 \mathrm{ppm}$ and at $8.9 \mathrm{ppm}$, corresponding to the aromatic ring present in $o$-AP and the proton of $\mathrm{OH}$ group is at $8.9 \mathrm{ppm}$. These indicate that the $o$-aminophenol was grafted onto the natural rubber. 


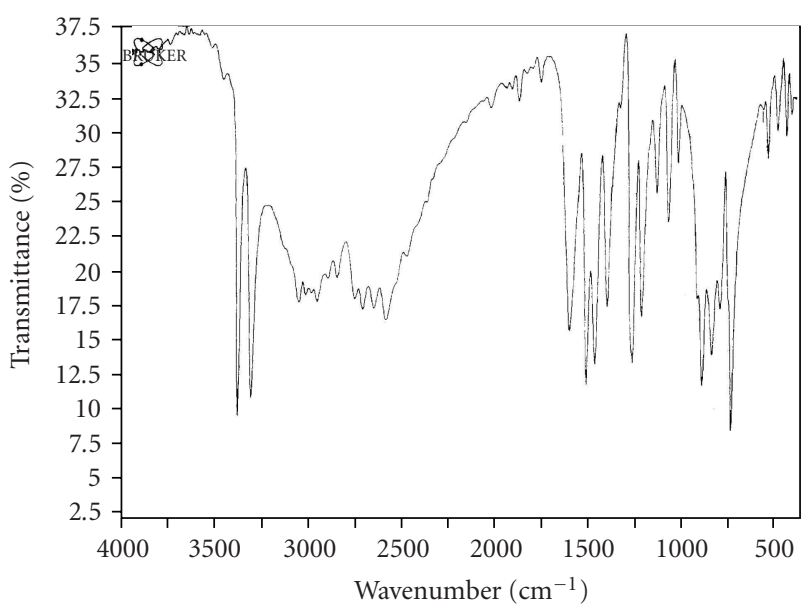

FIGURE 3: IR spectrum of $o$-aminophenol (o-AP).

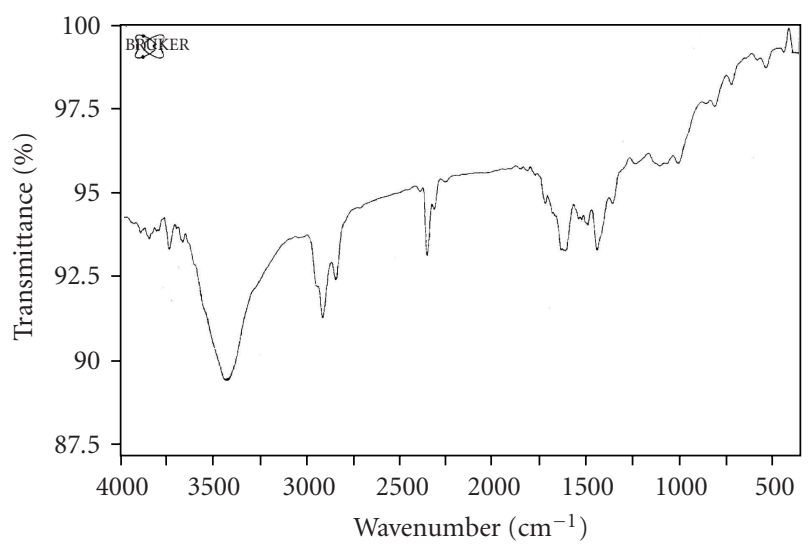

FIgURE 4: IR spectrum of natural rubber.

3.2. Effect of the Prepared Grafted Antioxidant, NR-g-o-AP, on the Mechanical Properties of Nitrile Rubber. Figure 8 shows the retained tensile strength as a function of the aging time and Figure 9 shows the relation between the retained elongation at break and the aging time.

The NBR-tested samples were aged to 2, 4, 6, and 7 days at $90^{\circ} \mathrm{C}$ in an aging oven. It is clear that the retained tensile strength and the retained elongation at break decreased with increasing the aging time durations from 2 days up to 7 days for the NBR vulcanizates containing the commercial antioxidant, $\mathrm{PBN}$, and the prepared grafted antioxidant, natural rubber-graft-o-aminophenol, as well as the control vulcanizate. Because the aging time duration has undesirable effect on the mechanical properties of the NBR vulcanizates, increase the ultrasonic attenuation coefficient as shown in Figure 10, and cleavage the crosslinking density between the chains of the NBR vulcanizates $[4,12]$.

Figures 8 and 9 indicate that the retained tensile strength and the retained elongation at break of the NBR vulcanizate which contain the grafted antioxidant NRgraft-o-AP are higher than both of the NBR vulcanizate which contains PBN as commercial antioxidant and the

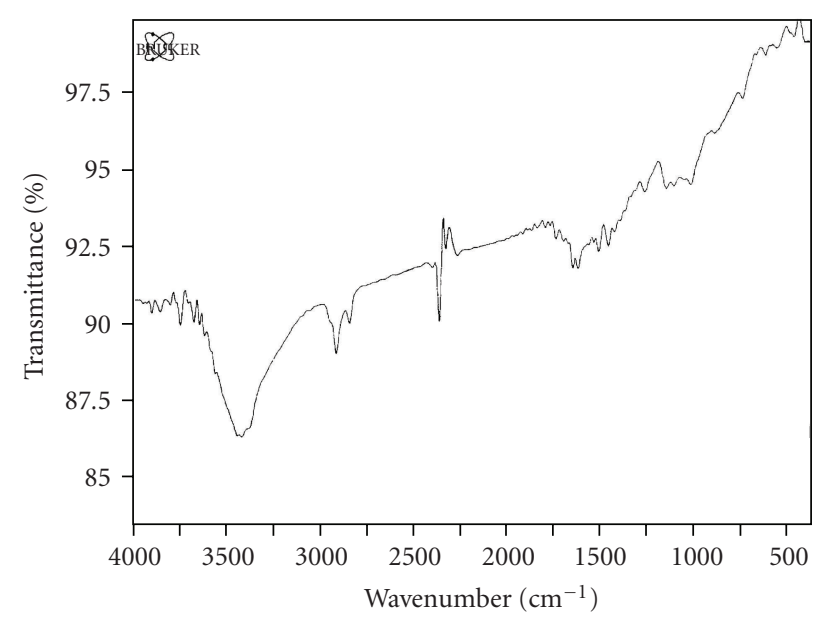

FIGURE 5: IR spectrum of natural rubber-g-o-aminophenol (NR-g$o$-AP).

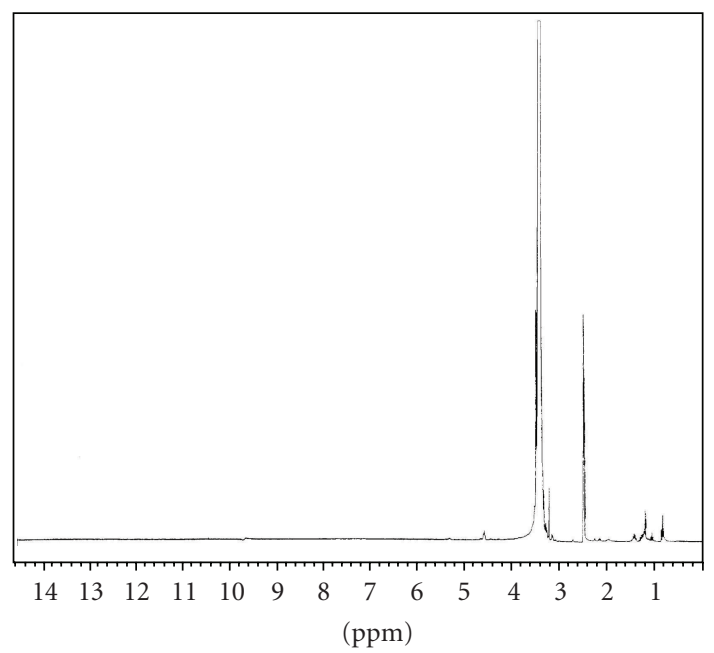

FIgURE 6: ${ }^{1} \mathrm{H}$ NMR spectrum of natural rubber.

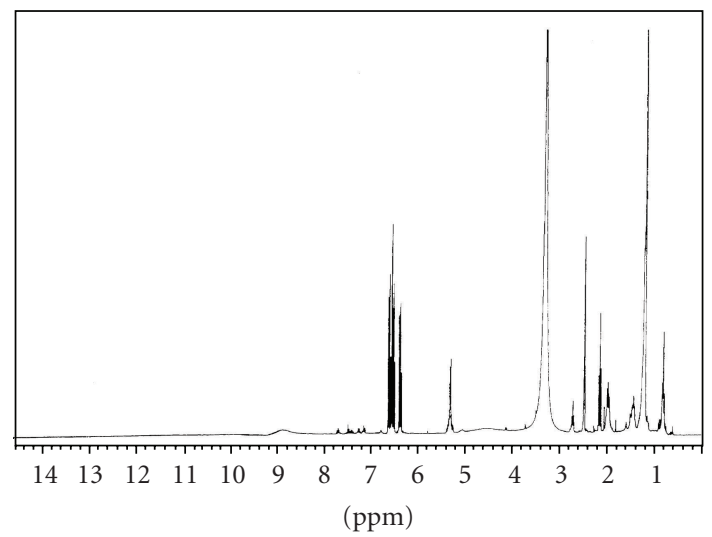

FIGURE 7: ${ }^{1} \mathrm{H}$ NMR spectrum of natural rubber-g-o-aminophenol (NR-g-o-AP). 


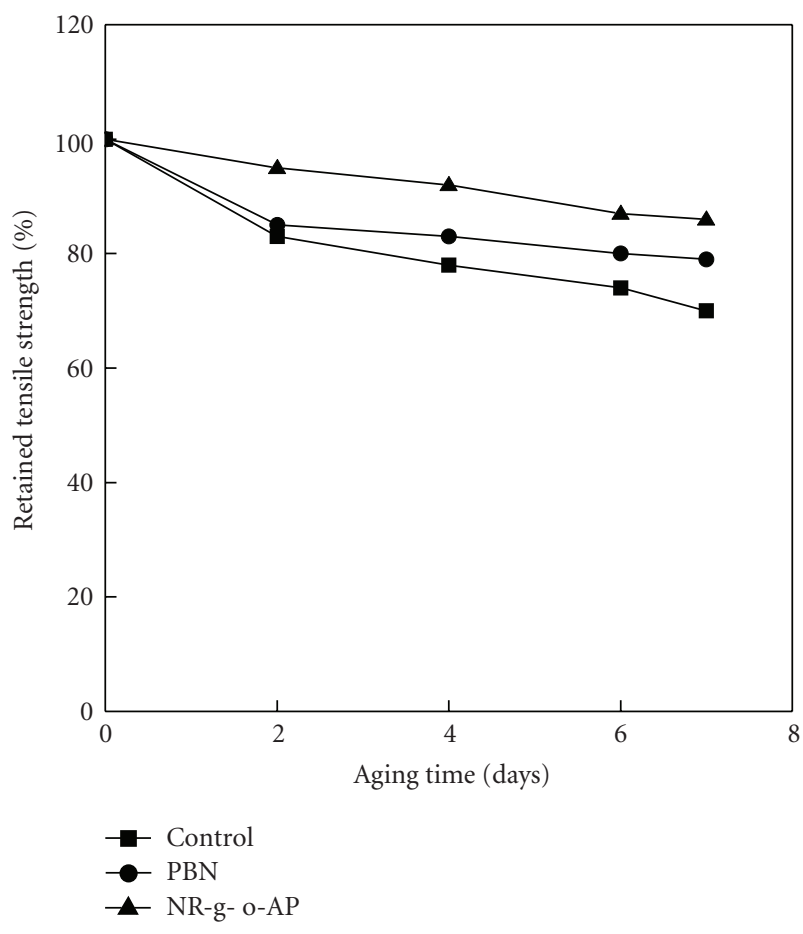

FIGURE 8: Relation between retained tensile strength and aging time for NBR vulcanizates containing PBN, NR-graft-o-AP, and control vulcanizate.

control vulcanizate. Because the $o$-aminophenol part in the prepared NR-graft-o-AP was oxidize, quinoneimines is the first product of the oxidation of $o$-Aminophenol and also has antioxidant activity [13]. The antioxidant activity of quinonimines can be explained by considering their capacity to react with another peroxy radical or to give addition reactions with substrates containing reactive- $\mathrm{CH}$ groups $[5]$.

3.3. Effect of the Prepared Grafted Antioxidant, NR-grafto-AP, on the Ultrasonic Attenuation Coefficient of Nitrile Rubber. Figure 10 shows the relation between the ultrasonic attenuation coefficient, and the aging time for NBR Vulcanizates.

Figure 10 shows that the NBR vulcanizate containing the NR-graft-o-AP has relatively lower ultrasonic attenuation coefficient compared with both the NBR vulcanizate containing PBN and the control vulcanizate. when the degradation of NBR chains increased, the homogeneity of NBR vulcanizate decreased and the NBR vulcanizate became more amorphous. It is clear that the ultrasonic attenuation coefficient increased with increasing the time of the thermal aging from 2 to 7 days. Therefore, it can be said that thermal aging activates molecules motion that promotes inherent weak point defect (e.g., voids) in the material to form minute cracks (stress raisers). Over periods of thermal aging, many sites of weak point defect can be traced to form the minute cracks. By increasing aging time, these minute cracks can grow and coalesce together to built main crack causing the fracture $[10,14]$.

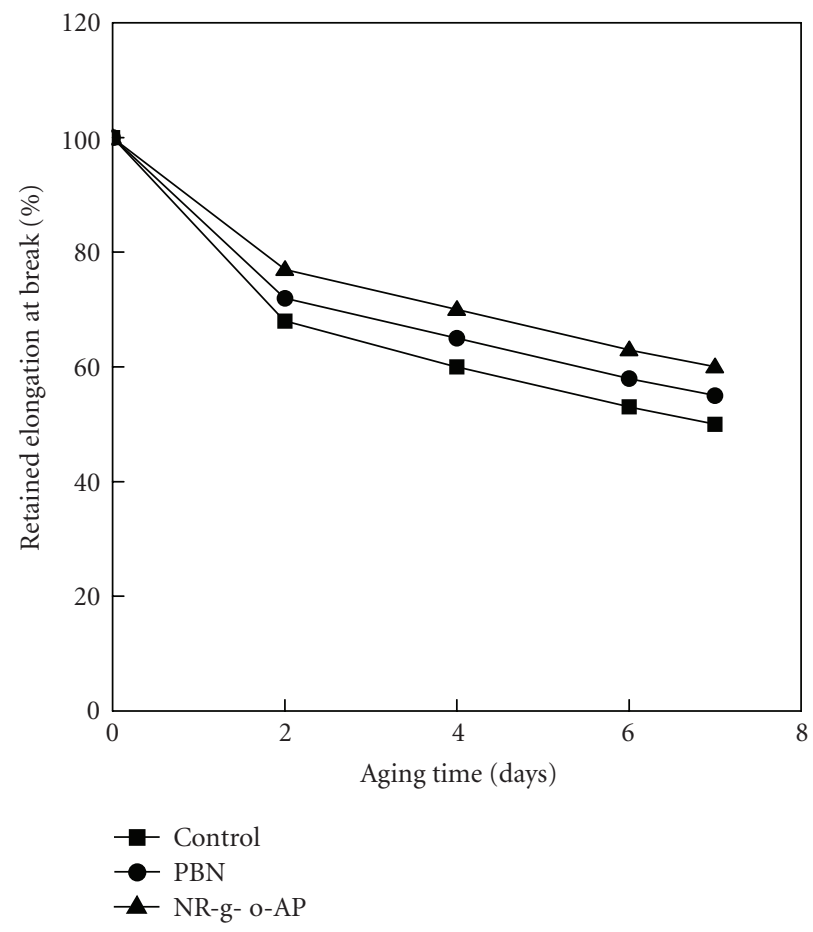

FIGURE 9: Relation between retained elongation at break and aging time for NBR vulcanizates containing PBN, NR-graft-o-AP, and control vulcanizate.

TABLE 2: Characterization of change $\alpha$.

\begin{tabular}{lccc}
\hline $\begin{array}{c}\text { Properties } \\
\text { Samples }\end{array}$ & Onset temp. ${ }^{\circ} \mathrm{C}$ & $\begin{array}{c}\text { Change } \alpha \\
\text { Endsed temp. }{ }^{\circ} \mathrm{C}\end{array}$ & Weight loss \% \\
\hline A1 & 178 & 376.2 & 5.75 \\
A2 & 200 & 384.2 & 6.05 \\
A3 & 215 & 380.3 & 5.04 \\
\hline
\end{tabular}

TABLE 3: Characterization of change $\beta$.

\begin{tabular}{lccc}
\hline $\begin{array}{c}\text { Properties } \\
\text { Samples }\end{array}$ & Onset temp. ${ }^{\circ} \mathrm{C}$ & $\begin{array}{c}\text { Change } \beta \\
\text { Endsed temp. }{ }^{\circ} \mathrm{C}\end{array}$ & Weight loss \% \\
\hline A1 & 376.2 & 492.3 & 67.34 \\
A2 & 384.2 & 505.9 & 65.81 \\
A3 & 380.3 & 502.9 & 61.94 \\
\hline
\end{tabular}

3.4. Effect of the Prepared Grafted Antioxidant, NR-graft-o-AP, on the Thermal Stability of Nitrile Rubber. Thermograms, of control mix, NBR mixes containing PBN, and NR-g-o-AP are given in Figure 11.

Degradation of NBR vulcanizates occurred in two steps, $\alpha$ and $\beta$ accompanied by weight loss. The first step degradation, change $\alpha$, starts at about $178^{\circ} \mathrm{C}$ and is completed at $384.2^{\circ} \mathrm{C}$. Change $\alpha$ is due to the loss of plasticizer and other ingredients and it corresponds to the volatilization of 5.04\%$6.05 \%$ of NBR content as shown in Table 2 .

The second step, change $\beta$, degradation starts at $376.2^{\circ} \mathrm{C}$ and is completed at $505.9^{\circ} \mathrm{C}$. Change $\beta$ is due to the degradation of NBR vulcanizate at higher temperatures that 


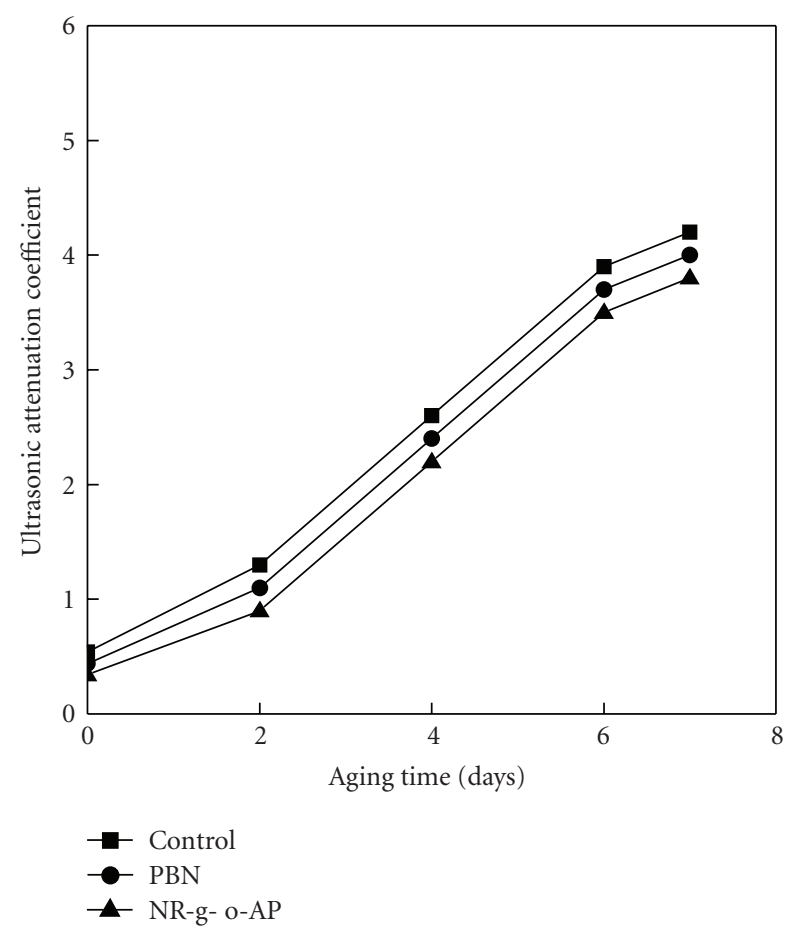

FIGURE 10: Relation between ultrasonic attenuation coefficient and aging time for NBR vulcanizates containing PBN and NR-graft-oAP.

leads to volatile products and also it is accompanied by weight loss for different NBR vulcanizates. Moreover, the thermal characterization of change $\beta$ is shown in Table 3 .

It is clear that the second step of degradation occurs dramatically compared with first step degradation.

These results indicate the superior efficiency of the prepared NR-graft-o-AP to protect NBR against thermal treatment where that is much better than the commercial antioxidant PBN and control mix, respectively.

Thermogravimetric curves were analysed mathematically to determine the nonisothermal kinetic parameters of the pyrolysis reactions. The function of the weight fraction LnLn $W_{o} / W$ was plotted versus the temperature factor, $\theta$. The activation energy of pyrolysis process was calculated from the slope of this straight line according to (3):

$$
\operatorname{Ln} \operatorname{Ln} \frac{W_{o}}{W}=\frac{\Delta E \theta}{R T_{s}^{2}}
$$

where $W_{o}$ and $W$ are the initial weight and the weight at a given temperature, respectively. $R$ is the gas constant, $E$ is the activation energy, $\theta$ is a temperature factor given as $\theta=T-$ $T_{s}$ [15], and $T_{s}$ is the reference temperature. The values of the reference temperature, $T_{s}$, at which the maximum rate of degradation occurred, and the values of the activation energy $(\Delta E)$ were described in Table 4.

They show that the antioxidant NR-graft-o-AP has the higher activation energy ( $\equiv 101.72 \mathrm{Kj} / \mathrm{mole})$ compared with commercial antioxidant, $\mathrm{PBN}$ ( $\equiv 63.46 \mathrm{Kj} / \mathrm{mole}$ ), and finally the control mix ( $\equiv 52.92 \mathrm{Kj} /$ mole). These results come in a

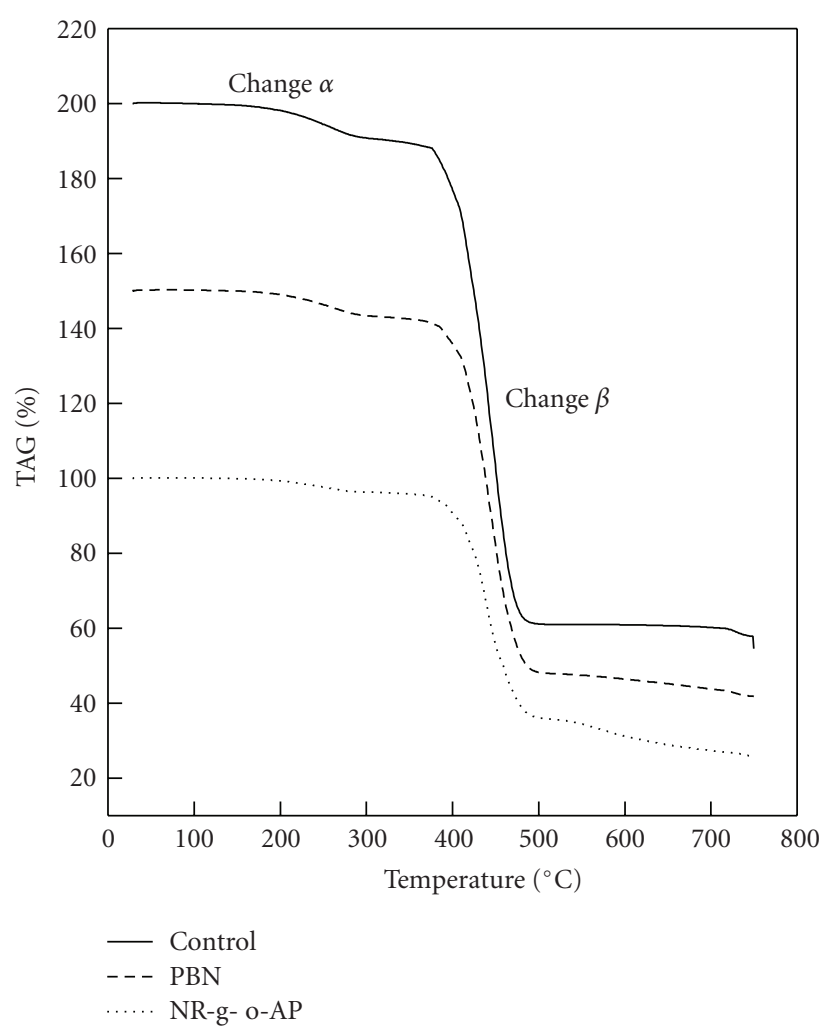

FIGURE 11: TGA thermogram for for NBR vulcanizates containing PBN, NR-g-o-AP, and control vulcanizate.

TABLE 4: The activation energy of NBR vulcanizates containing PBN, NR-graft- $o$-AP, and control vulcanizate.

\begin{tabular}{lcc}
\hline Sample & $T_{s}$ & $E \mathrm{Kj} / \mathrm{mole}$ \\
\hline A1 & 434 & 52.92 \\
A2 & 441 & 63.46 \\
A3 & 445 & 101.72 \\
\hline
\end{tabular}

good agreement with those obtained with the mechanical properties where NR-graft-o-AP is a superior antioxidant.

\section{Conclusions}

The prepared NR-graft-o-AP is very active antioxidant in NBR copolymer if it is compared with the commercial antioxidant, PBN. The NBR vulcanizate which contains the grafted antioxidant, NR-graft-o-AP, has higher mechanical properties than the NBR vulcanizate which contains PBN as commercial antioxidant and the control vulcanizate, respectively.

This study showed that thermal aging has significant effect on the ultrasonic attenuation coefficient. In addition, it promotes the degradation of NBR chains causing the decreasing of the mechanical properties. The results of thermal analysis indicate the superior efficiency of the prepared NR-graft- $o$-AP to protect NBR against thermal treatment much better than the commercial antioxidant PBN and control mix, respectively. 


\section{References}

[1] A. Jha and A. K. Bhowmick, "Thermal degradation and ageing behaviour of novel thermoplastic elastomeric nylon-6/acrylate rubber reactive blends," Polymer Degradation and Stability, vol. 62, no. 3, pp. 575-586, 1998.

[2] X. H. Zhang, L. H. Huang, S. Chen, and G. R. Qi, "Improvement of thermal properties and flame retardancy of epoxy-amine thermosets by introducing bisphenol containing azomethine moiety," eXPRESS Polymer Letters, vol. 1, no. 5, pp. 326-332, 2007.

[3] D. Forsström, T. Reitberger, and B. Terselius, "Thermooxidative stability of polyamide 6 films-part II: chemiluminescence techniques," Polymer Degradation and Stability, vol. 67, no. 2, pp. 255-261, 2000.

[4] A. A. El-Wakil, "Synthesis, characterization, and evaluation of natural rubber-graft-N-(4- aminodiphenyl methane) acrylamide as an antioxidant," Journal of Applied Polymer Science, vol. 101, no. 2, pp. 843-849, 2006.

[5] J. M. Herdan, M. Stan, and M. Giurginca, "Grafting antioxidants: VIII. Antioxidant activity and grafting of some N(aryl)-2,6-di-tert-butylquinoneimines," Polymer Degradation and Stability, vol. 50, no. 1, pp. 59-63, 1995.

[6] Y. Ohkatsu and T. Nishiyama, "Phenolic antioxidants-effect of ortho-substituents," Polymer Degradation and Stability, vol. 67, no. 2, pp. 313-318, 2000.

[7] J. Pospisil and S. Nespurek, "Chain-breaking stabilizers in polymers: the current status," Polymer Degradation and Stability, vol. 49, no. 1, pp. 99-110, 1995.

[8] A. A. El-Wakil, "Study on effect of natural rubber-graft-1,2phenylenediamine as antioxidant on oxidation resistance for natural rubber," Polymer-Plastics Technology and Engineering, vol. 46, no. 6, pp. 661-666, 2007.

[9] ASTM D 412-98a, 1998.

[10] I. M. Ward, Mechanical Properties of Solid Polymers, John Wiley \& Sons, Chichester, UK, 2nd edition, 1983.

[11] A. Jha and A. K. Bhowmick, "Thermal degradation and ageing behaviour of novel thermoplastic elastomeric nylon-6/acrylate rubber reactive blends," Polymer Degradation and Stability, vol. 62, no. 3, pp. 575-586, 1998.

[12] A. A. El-Wakil, "Amelioration of acrylonitrile-butadiene copolymer properties using natural rubber graft paminophenol," Journal of Applied Polymer Science, vol. 104, no. 1, pp. 27-34, 2007.

[13] M. E. Cain, J. R. Gelling, G. T. Knight, and P. M. Lewis, "Quinone diimines: a novel class of scorch free antidegradants," Rubber Industry, vol. 8, pp. 216-226, 1975.

[14] M. A. Y. Barakat and A. A. El-Wakil, "Enhancement the thermal stability and the mechanical properties of acrylonitrilebutadiene copolymer by grafting antioxidant," in Proceedings of the 9th Cairo University International Conference on Mechanical Design and Production (MDP '08), 2008.

[15] H. H. Horowitz and G. Metzger, "A new analysis of thermogravimetric traces," Analytical Chemistry, vol. 35, no. 10, pp. 1464-1468, 1963. 

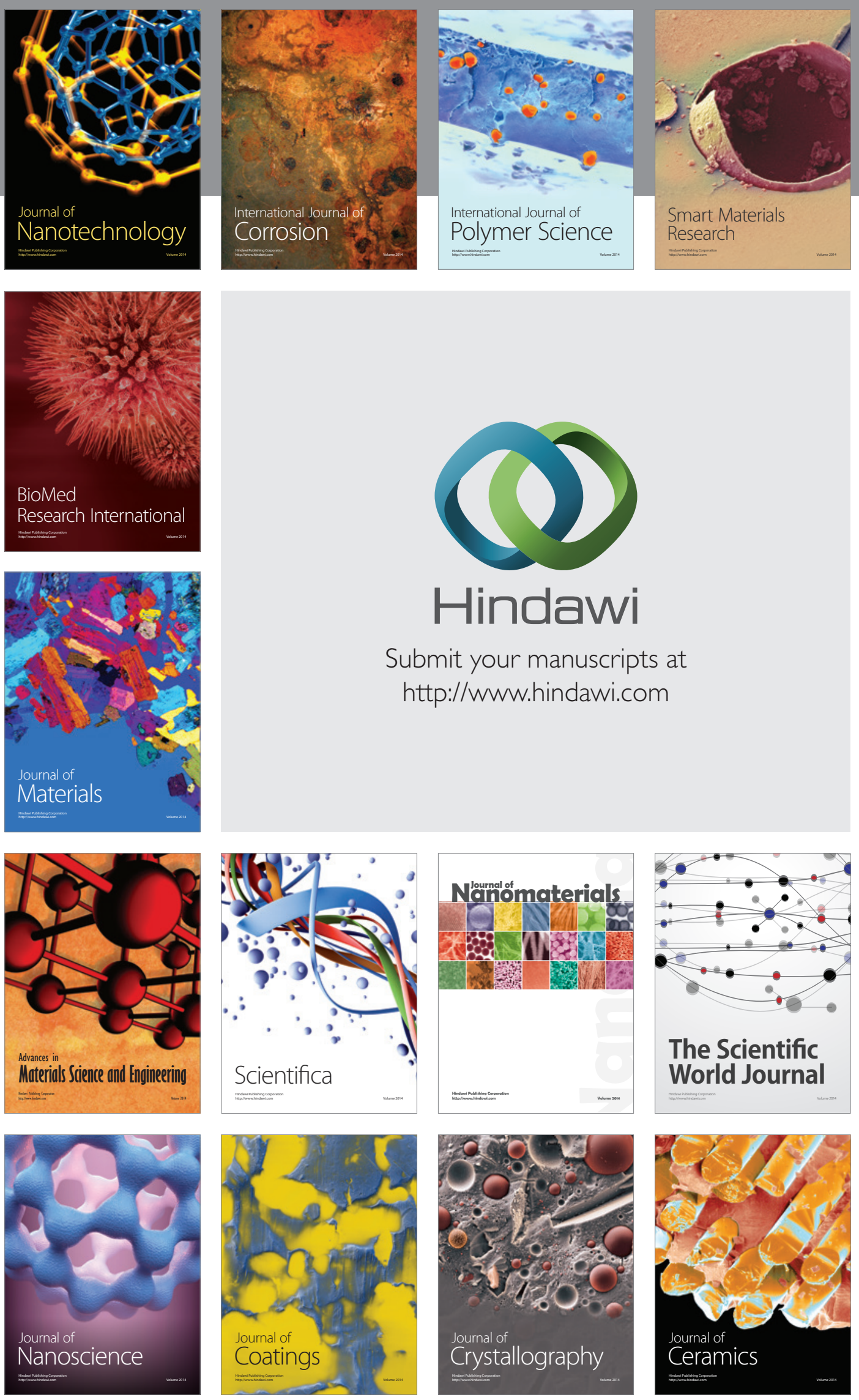

The Scientific World Journal

Submit your manuscripts at

http://www.hindawi.com

\section{World Journal}

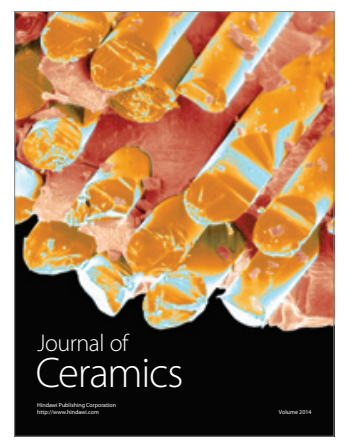

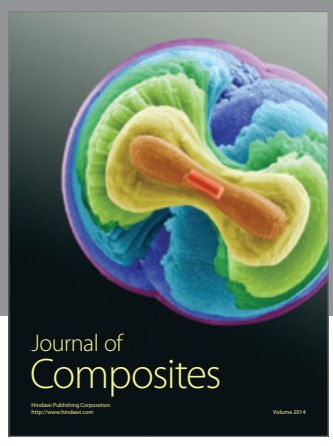
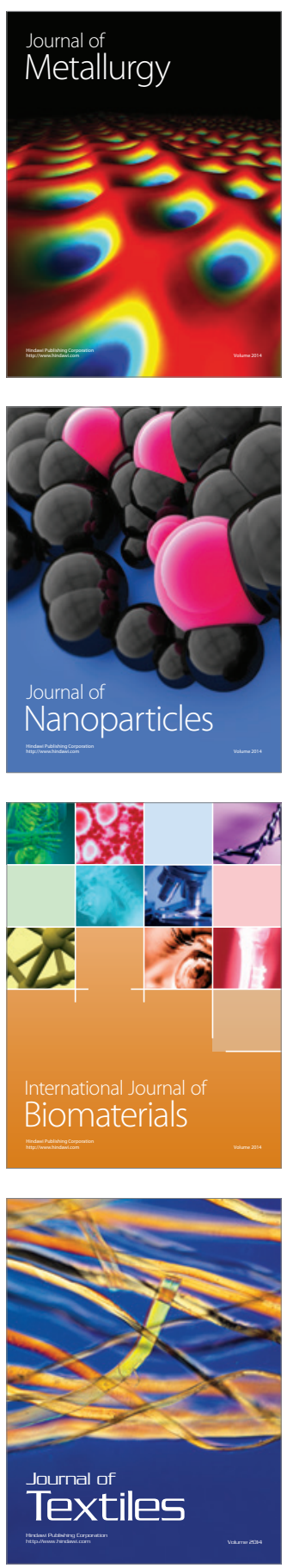